\title{
ANALISIS VARIASI KECEPATAN ANGIN TERHADAP KEAUSAN KAMPAS REM
}

\author{
Ahmad Syarafi*, Darmanto, Agung Nugroho \\ Jurusan Teknik Mesin , Fakultas Teknik, Universitas Wahid Hasyim \\ Jl. Menoreh Tengah X/22. Sampangan, Semarang 50236 \\ *Email : ahmadsyarafiofiq@gmail.com
}

\begin{abstract}
Abstrak
Kampas rem merupakan salah satu bagian dari kendaraan bermotor yang bekerja untuk memperlambat atau menghentikan laju kendaraan bermotor. Dalam konsep pengereman hal yang tidak dapat dihindarkan adalah sebuah keausan. Keausan terjadi apabila dua buah benda yang saling menekan dan saling bergesekan. Penelitian ini dilakukan untuk mengetahui seberapa besar pengaruh kecepatan angin terhadap volume dan laju keausan kampas rem, penelitian ini dengan menggunakan alat uji keausan kampas rem dengan variasi kecepatan angin 0, 5, 10, 15, $20 \mathrm{~km} / \mathrm{j}$ dengan beban pengereman $2 \mathrm{Kg}$. Durasi waktu pengujian yaitu 50 menit yang dilakukan penimbangan per10 menit. Hasil penelitian ini nilai volume keausan tertinggi terjadi pada variasi angin $0 \mathrm{~km} / \mathrm{j}$ sisi kampas A 102,69 $\mathrm{mm}^{3}$ dan sisi $B \quad 81,42 \mathrm{~mm}^{3}$, nilai rata-rata volume keausan yang terbesar terjadi pada variasi kecepatan angin $0 \mathrm{~km} / \mathrm{j}$ sisi A $67,631 \mathrm{~mm}^{3}$ dan sisi B 55,381 $\mathrm{mm}^{3}$, sedangkan nilai laju keausan yang terbesar terjadi pada variasi kecepatan angin $0 \mathrm{~km} / \mathrm{j}$ sisi A 1,1E-07 gr/s.mm² sisi B 9,6E-08 gr/s. $\mathrm{mm}^{2}$, nilai rata rata laju keausan terbesar terjadi pada variasi kecepatan angin $0 \mathrm{~km} / \mathrm{j}$ sisi A 8,63E-08 gr/s. $\mathrm{mm}^{2}$ sisi B 7,20E-08 $\mathrm{gr} / \mathrm{s} . \mathrm{mm}^{2}$, nilai volume keausan terkecil terjadi pada variasi angin $20 \mathrm{~km} / \mathrm{j}$ sisi kampas A $51,34 \mathrm{~mm}^{3}$ dan sisi B 46,21 $\mathrm{mm}^{3}$, nilai ratarata volume keausan yang terkecil terjadi pada variasi kecepatan angin $20 \mathrm{~km} / \mathrm{j}$ sisi A 35,062 $\mathrm{mm}^{3}$ dan sisi B 32,642 $\mathrm{mm}^{3}$, sedangkan nilai laju keausan yang terkecil terjadi pada variasi kecepatan angin $20 \mathrm{~km} / \mathrm{j}$ sisi A 3,7E-08 $\mathrm{gr} / \mathrm{s} . \mathrm{mm}^{2}$ sisi B 3,3E-08 $\mathrm{gr} / \mathrm{s} . \mathrm{mm}^{2}$, nilai rata rata laju keausan terkecil terjadi pada variasi kecepatan angin $20 \mathrm{~km} / \mathrm{j}$ sisi A 4,48E-08 gr/s.mm² dan sisi B 4,28E-08 $\mathrm{gr} / \mathrm{s} . \mathrm{mm}^{2}$
\end{abstract}

Kata kunci : kampas Rem, kecepatan angin, keausan

\section{PENDAHULUAN}

Kampas rem merupakan salah satu bagian dari kendaraan bermotor yang bekerja untuk memperlambat atau menghentikan laju kendaraan bermotor. Pada saat kendaraan melaju dengan kecepatan tinggi kampas rem menjadi komponen yang sangat penting untuk memperlambat atau menghentikan laju, jadi komponen ini berpengaruh terhadap keselamatan jiwa pengendara.

Keausan (wear) adalah hilangnya sebagian material dari permukaan benda padat yang ada gerakan mekanik. Keausan dapat diartikan sebagai hilangnya sebagian material akibat interaksi mekanik dua permukaan yang bergerak sliding dan dibebani (Blau, 1997). Dalam konsep pengereman hal yang tidak dapat dihindarkan adalah sebuah keausan. Keausan terjadi apabila dua buah benda yang saling menekan dan saling bergesekan (Khurmi \& Gupta, 2005). Keausan yang lebih besar terjadi pada bahan yang lebih lunak. Faktor-faktor yang mempengaruhi keausan adalah suhu, kecepatan, tekanan, dan kekerasan permukaan. Semakin tinggi suhu kampas rem maka material akan semakin mudah aus, begitu pula sebaliknya.

Pendinginan dibutuhkan pada saat pengereman agar terhindar dari kegagalan pengeraman. kampas rem untuk menjaga suhu kampas rem, suhu rendah dapat memperlambat keausan kampas rem dan mencegah rem blong pada saat dilakukan pengereman. Tujuan penelitian ini adalah untuk mengetahui pengaruh kecepatan angin terhadap volume dan laju keausan kampas rem .

\section{METODOLOGI}

Dalam pengujian ini menggunakan material kampas rem jenis pad set FR dengan Kode Part 06455KR3404 seperti pada gambar 2. Putaran Disc Brake (lihat 
gambar 3) dijaga konstan pada 1102,2 rpm dengan beban pengereman konstan yaitu 19.62 N. Durasi pengujian gesek selama 50 menit dilakukan pengambilan data selama 10 menit sekali. Sebagai media pendingin digunakan blower fan dan kecepatan angin divariasikan $0 \mathrm{~km} / \mathrm{jam}, 5 \mathrm{~km} / \mathrm{jam}, 10$ $\mathrm{km} / \mathrm{jam}, 15 \mathrm{~km} / \mathrm{jam}$, dan $20 \mathrm{~km} / \mathrm{jam}$.

Alat uji keausan kampas rem cakram seperti terlihat pada gambar 1. Digunakan dalam penelitian ini. Alat ini terdiri dari motor listrik untuk memutar disc dan inverter sebagai pengatur kecepatan motor. Untuk mengatur putaran disc agar sesuai yang diinginkan maka motor dilengkapi dengan inverter. Hasil dari keausan material disc yang di dapat digunakan sebagai acuan dalam penelitian ini. Adapun bagian dan fungsi dari alat uji keausan kampas rem seperti ditunjukkan pada Tabel 1.

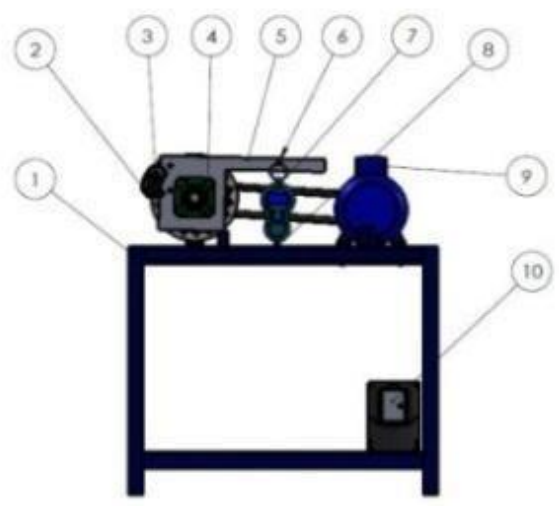

Gambar 1. Alat uji keausan kampas rem

Keterangan gambar 1.
1. Rangka
6. Pengunci Atas
2. Disc
7. Timbangan Digital
3. Caliper
8. Pengunci Bawah
4. Bantalan
9. Motor Listrik
5. Lengan Beban
10. Inverter

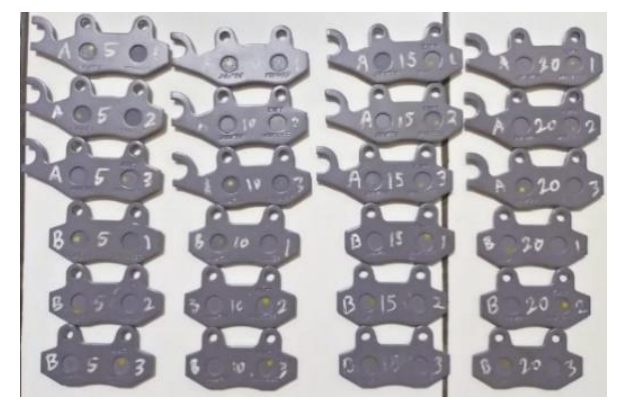

Gambar 2. Kampas rem

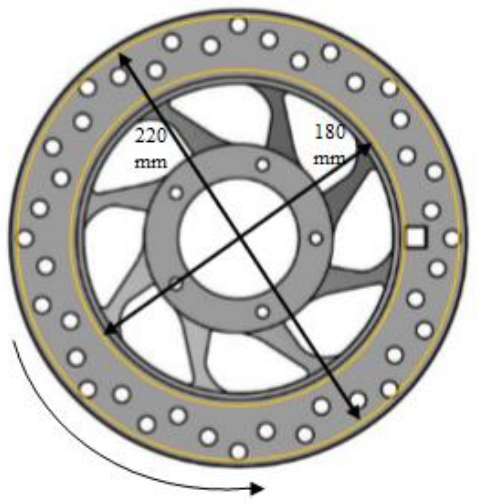

Gambar 3. piringan rem cakram

Bentuk kekasaran kampas rem baik sebelum dan sesudah melakukan pengujian spesimen dilakukan foto makro untuk mengetahui bentuk awal dari spesimen yang akan diuji dan bentuk kekasaran setelah diuji. Tingkat kekasaran permukaan kampas rem diukur menggunakan roughness surface tester seperti pada pada gambar 5 .

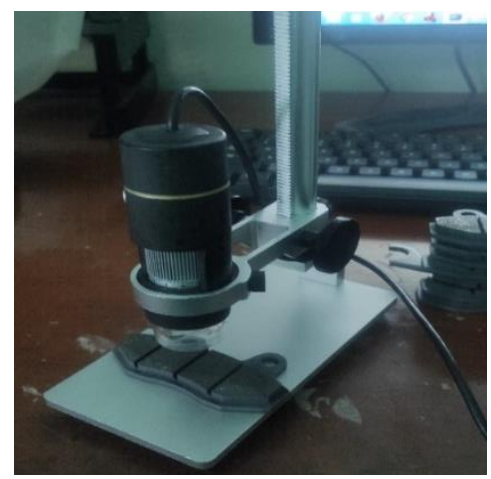

\section{Gambar 4. mikroskop metalografi}

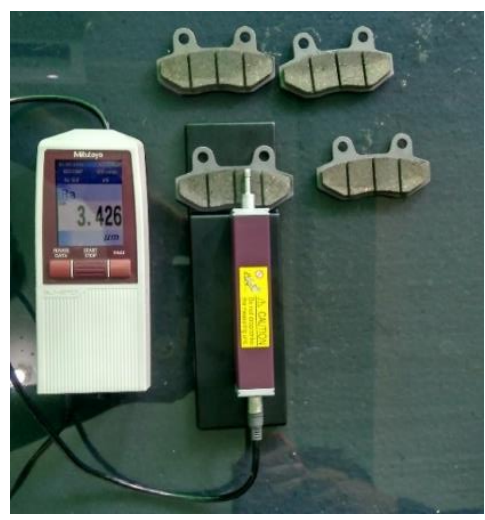

Gambar 2. Roughness surface tester 


\section{HASIL DAN PEMBAHASAN}

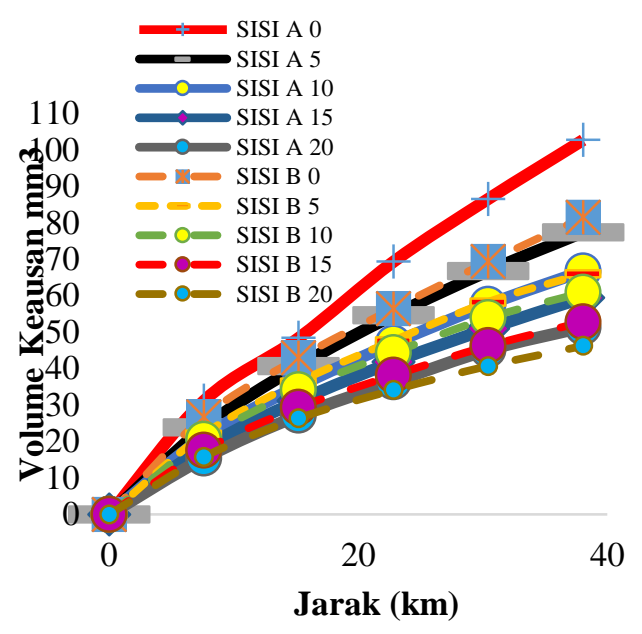

\section{Gambar 6. Perbandingan Volume Keausan Kampas Rem}

Dari gambar 6 menunjukkan bahwa volume keausan terbesar terjadi pada variasi kecepatan angin $0 \mathrm{~km} / \mathrm{j}$ kemudian disusul secara berurutan dengan variasi kecepatan angin $5,10,15$, dan $20 \mathrm{~km} / \mathrm{j}$ yang memiliki nilai volume keausan sisi A $102,69 \mathrm{~mm}^{3}$, $77,38 \mathrm{~mm}^{3}, 66,75 \mathrm{~mm}^{3}, 59,41 \mathrm{~mm}^{3}, 51,34$ $\mathrm{mm}^{3}$ dan sisi B $81,42 \mathrm{~mm}^{3}, 66,01 \mathrm{~mm}^{3}$, $60,88 \mathrm{~mm}^{3}, 52,81 \mathrm{~mm}^{3}, 46,21 \mathrm{~mm}^{3}$.

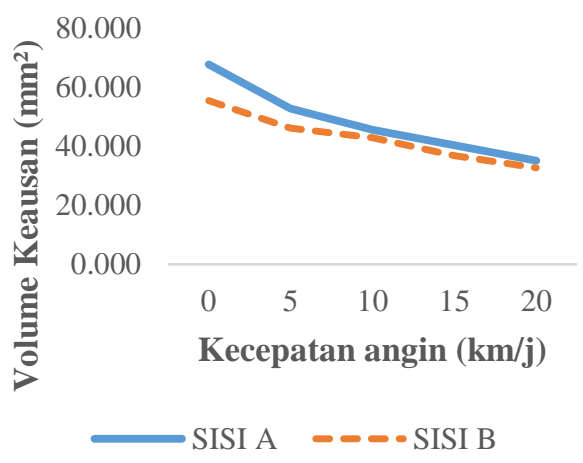

\section{Gambar 7. Volume Keausan Kampas}

Dari gambar 7 menunjukkan bahwa volume rata-rata keausan terbesar terjadi pada variasi kecepatan angin $0 \mathrm{~km} / \mathrm{j}$ kemudian disusul secara berurutan dengan variasi kecepatan angin $5,10,15$, dan 20 $\mathrm{km} / \mathrm{j}$ yang memiliki nilai volume keausan sisi A $67,631 \mathrm{~mm}^{3}, 52,667 \mathrm{~mm}^{3}, 45,552$ $\mathrm{mm}^{3}, 40,344 \mathrm{~mm}^{3}, 35,062 \mathrm{~mm}^{3}$ dan sisi B $55,381 \mathrm{~mm}^{3}, 46,065 \mathrm{~mm}^{3}, 42,764 \mathrm{~mm}^{3}$, $36,823 \mathrm{~mm}^{3}, 32,642 \mathrm{~mm}^{3}$.

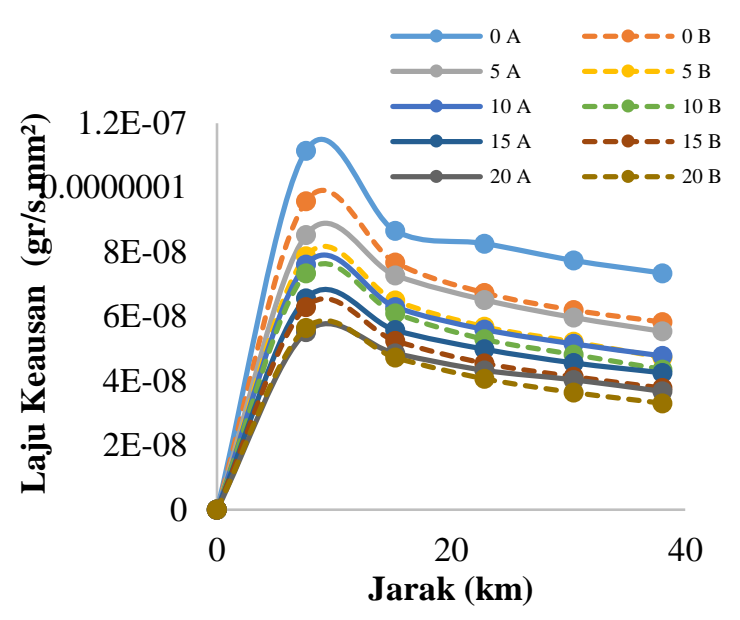

\section{Gambar 8. Perbandingan Laju Keausan}

Volume rata-rata keausan terbesar terjadi pada variasi kecepatan angin $0 \mathrm{~km} / \mathrm{j}$ kemudian disusul secara berurutan dengan variasi kecepatan angin $5,10,15$, dan 20 $\mathrm{km} / \mathrm{j}$ yang memiliki nilai volume keausan sisi A $67,631 \mathrm{~mm}^{3}, 52,667 \mathrm{~mm}^{3}, 45,552$ $\mathrm{mm}^{3}, 40,344 \mathrm{~mm}^{3}, 35,062 \mathrm{~mm}^{3}$ dan sisi B $55,381 \mathrm{~mm}^{3}, 46,065 \mathrm{~mm}^{3}, 42,764 \mathrm{~mm}^{3}$, $36,823 \mathrm{~mm}^{3}, 32,642 \mathrm{~mm}^{3}$.

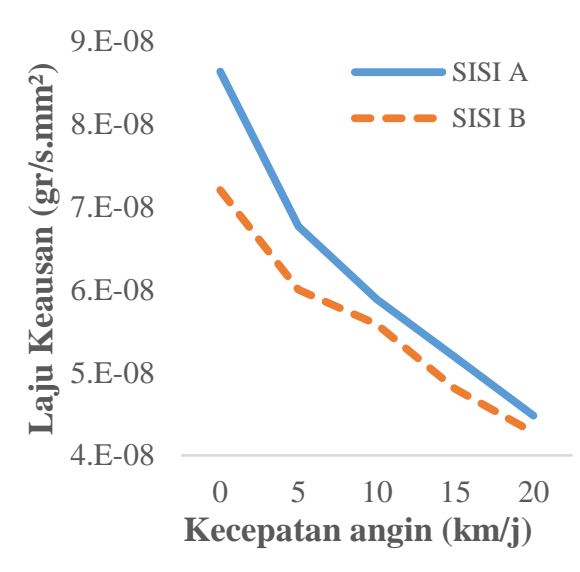

\section{Gambar 9. Perbandingan Rata-Rata Laju Keausan Kampas Rem}

Dari gambar 9 dapat dilihat bahwa laju rata-rata keausan akan semakin berkurang jika kecepatan pendinginannya dinaikkan. Hal ini sejalan dengan penelitian yang dilakukan oleh (Multazam dkk., 2012). Laju keausan terbesar terjadi pada variasi kecepatan angin $0 \mathrm{~km} / \mathrm{j}$ kemudian laju keausan terkecil pada kecepatan $20 \mathrm{~km} / \mathrm{j}$. 


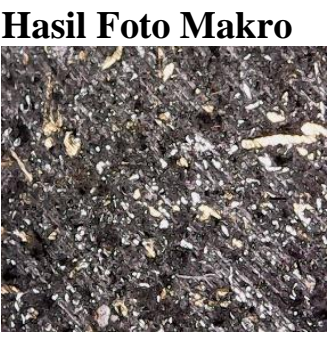

(a)

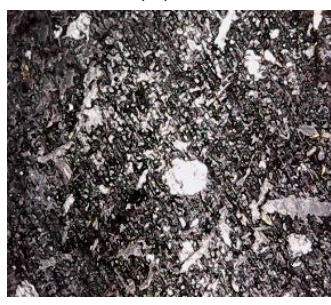

(c)

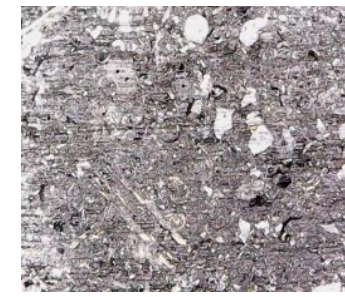

(e)

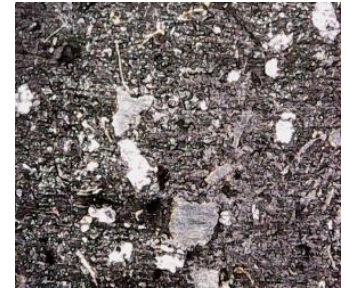

(b)

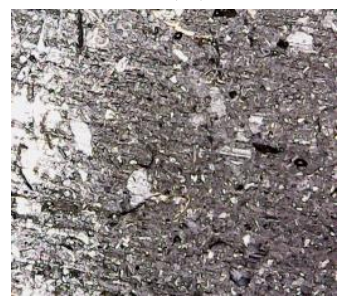

(d)

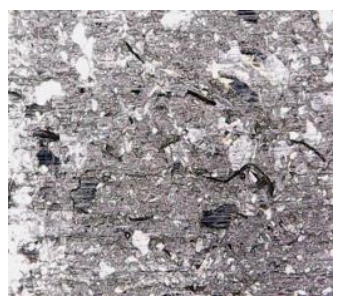

(f)

\section{Gambar 9. Perbandingan Rata-Rata Laju Keausan Kampas Rem}

Keterangan gambar 9.
a. Kampas Sebelum Pengujian
b. Sisi A kecepatan angin $0 \mathrm{~km} / \mathrm{j}$
c. Sisi A kecepatan angin $5 \mathrm{~km} / \mathrm{j}$
d. Sisi A kecepatan angin $10 \mathrm{~km} / \mathrm{j}$
e. Sisi A kecepatan angin $15 \mathrm{~km} / \mathrm{j}$
f. Sisi A kecepatan angin $20 \mathrm{~km} / \mathrm{j}$

Secara struktur dapat dilihat pada gambar 10 bahwa terjadi degradasi yang cukup besar dari material kampas rem saat tidak diberikan pendinginan udara sehingga menyebabkan permukaan kampas tergerus oleh gesekan disk brake, hal ini sejalan dengan penelitian dari (Taufik dkk., 2018) dan (Sayid, 2015) yang menyatakan bahwa penurunan suhu kampas akan berpengaruh terhadap laju keausan kampas.

\section{PENUTUP}

Kesimpulan

Volume Keausan terbesar terdapat pada kampas sisi A tanpa variasi kecepatan angin karena semakin rendah kecepatan angin maka volume keausannya semakin besar, dan semakin tinggi kecepatan angin maka maka volume keausannya semakin kecil.

Laju keausan terbesar terdapat pada kampas sisi A tanpa variasi angin karena semakin rendah kecepatan angin maka semakin tinggi laju keausannya, sebaliknya semakin tinggi kecepatan anginnya maka semakin rendah laju keausannya. Material kampas sisi A dan sisi B keausan tidak seragam karena tekanan pada kampas rem sisi A dan sisi B tidak sama.

\section{DAFTAR PUSTAKA}

Blau, P. J. (1997). Fifty years of research on the wear of metals. Tribology International.

https://www.sciencedirect.com/scienc e/article/pii/S0301679X9600062X

Khurmi, R. S., \& Gupta, J. K. (2005). A textbook of machine design. 182.160.97.198.

http://182.160.97.198:8080/xmlui/bitst ream/handle/123456789/1338/Index.p $\mathrm{df}$ ?sequence $=18$

Multazam, A., Zaenuri, A., \& Sujita. (2012). Analisa Pengaruh Variasi Merek Kampas Rem Tromol dan Kecepatan Sepeda Motor Honda Supra X125 Terhadap Keausan Kampas Rem. Dinamika Teknik Mesin, 2(2).

Sayid. (2015). Analisis Keausan Kampas Rem Cakram Aasbestos dan non Asbestos dengan Variasi Beban Pengereman dan Berat Pengendara. Teknik Mesin Universitas Mataram.

Taufik, A., Darmanto, \& Imam Syafa'at. (2018). Analisis Keausan Kampas Rem pada Disk Break dengan Variasi Kecepatan. 